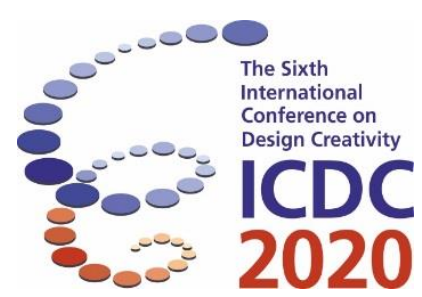

\title{
Relationship between design thinking and personality traits
}

\author{
Rui Mao ${ }^{1}$, Yuichi Washida ${ }^{1}$ and Nanami Furue ${ }^{2}$ \\ ${ }^{1}$ School of Business Administration, Hitotsubashi University, Tokyo, Japan \\ ${ }^{2}$ Department of Management, Tokyo University of Science, Tokyo, Japan
}

\begin{abstract}
This paper is an attempt to gain better insight into design thinking from a micro-viewpoint through the association of design thinking with human beings' personality traits. Based on previous research, we conjecture that personality traits are also associated with the capacity for utilizing design thinking. To test our hypothesis, we focused on the five-stage Design Thinking model proposed by the d.school and utilized FFM (Five-Factor Model) to describe personalities. 28 students, who have experiences of design thinking activities, participated in the study. We used correlation analysis and observed the significant relationship between personality traits and individuals' capacity for utilizing design thinking.
\end{abstract}

Keywords: Design thinking, Personality traits, Five-factor model

\section{Introduction}

In recent years, design thinking has become very popular in the IT, business, education and medicine fields. Since Rowe used the term "design thinking" as the title of his 1987 book, the concept has been part of design researchers' collective consciousness (Rowe, 1987).

As design thinking research developed historically, the first Design Thinking Research Symposium (DTRS) was an opportunity to explore research on design and design methodology from the perspective of design thinking (Cross et al. 1992). The second DTRS symposium sought to advance multiple understandings of design thinking by establishing a common empirical basis (Cross et al, 1996). Multiple design-thinking models have gained prominence over the past thirty years of research. These have been based on decidedly different ways of viewing design situations and employed theories and models adopted from design methodology, psychology, education, etc. Generally speaking, these streams of research have create a rich and varied understanding of a very complicated human reality. Over the past decade, design thinking has been identified as an exciting new paradigm for addressing problems in both innovation and general management (Micheli et al., 2019).This enthusiasm for applying design thinking has created a sudden demand for clear and definite knowledge about design thinking (including the essence and toolbox). This has posed quite a problematic challenge for a design research community that has been reluctant to oversimplify design thinking, and cherished the multiple perspectives.

However, remarkably, little empirical research has been conducted into whether individual characteristics moderate or mediate the relationship between design thinking and performance (Micheli et al., 2019). This paper is an attempt to gain better insight into design thinking from a micro-viewpoint through the association of design thinking with human beings' personality traits. 


\section{Literature review}

\subsection{Ambiguity in Design Thinking}

It is noteworthy that, despite compelling calls for the adoption of design thinking, a generally accepted definition of the concept has still not been definitively formulated (Micheli et al., 2019). Some scholars have regarded it as an organizational attribute, whereas others conceive of it at the individual level, highlighting the traits of "design thinkers" (Luchs, 2016).

A survey of previous research finds two distinct discourses on design thinking: one in design-based scholarly literature, and the other in the widely accessible business media (Johansson et al., 2013).

The first discourse is so-called designerly thinking. It refers to the academic construction of a professional designer's practice (practical skills and competence) and theoretical reflections about how to interpret and characterize this non-verbal competence. In contrast, there is a discourse on so-called design thinking. This term is reserved for treatment of the concept where design practice and competence are employed outside of the design context (including art and architecture) for and with people who do not have a scholarly background in design, particularly those engaged in management. In this study, we focus on the latter, i.e. the management discourse. In general, management designthinking discourse is not as well thought-out and robust as contributions to designerly-thinking discourse, which scholars have argued and reflected on for several decades. In one interpretation, design thinking may also be understood as a way for managers to understand design in a more straightforward way than through the design management discourse built on a managerial platform.

\subsection{Design Thinking in Managerial Discourse}

In managerial discourse, design thinking is presented as a general human-centered approach to problem solving, creativity and innovation (e.g., Brown, 2009).Underpinning this approach is the idea of empathy: designers are perceived as being willing and able to understand and interpret the perspectives of end users and the problems they face. In doing so, Brown suggests, they more or less feel their way through to a new solution. According to Brown, a successful design outcome exists at the intersection of three concerns: what is desirable from the user's perspective, what is technically feasible, and what is commercially viable for the organization (Brown, 2009). In so doing, this approach introduces a key, yet often ignored, paradox. On the one hand, designers are positioned as vital interpreters of what end users "need." They are expected to do this by employing ethnographically-inspired techniques that help them understand the user's perspectives and situated actions. Construed in this way, design thinking fails to reference wider theories of society and misses opportunities to illuminate the context into which the designer is intervening.

In The Design of Business (2009), Roger Martin presents a different way of conceiving design thinking. Martin argues that design thinking gives business a competitive advantage. In contrast to Brown who describes what professional designers do and make as well as what they are attentive to, Martin focuses on methods used by successful managers that he interviewed and examines how firms function as a whole. His version of design thinking deals less with individual cognitive styles and does not present sets of material practices; rather, he focuses on systems of organization. In this way he echoes arguments put forward by others teaching and researching in a business school setting (e.g. Boland and Collopy, 2004). Martin sees design thinking as combining abductive, as well as inductive and deductive, reasoning. This is particularly of value to businesses tackling the well-established challenge of focusing on either exploitation or exploration (cf. March, 1991).

\subsection{Design Creativity and Design Thinking}

Creativity is an essential element in the process of designing. It is also a captivating and stimulating aspect of human thinking. Nevertheless, definitions of creativity are multiple and varied, and factors influencing creativity myriad and various. For instance, creativity has been defined as the ability to restructure old ideas to produce singular inventions (Heap, 1989) and the ability to apply original thinking (Coyne, 1995). It has also been defined as "a state of being and adaptation of personal skill sets that enables an individual to synthesize novel connections and express meaningful outcomes" 
(Hawthorne et al., 2013). Creative thinking is also associated with the capacity to look critically at reality, explore unconventional alternatives, and perceive situations from innovative perspectives (Csikszentmihalyi, 1997).

On the other hand, creativity is an essential element in design problem-solving. One of the primary reasons is that design is a complex and ill-structured activity, where problems cannot be solved through the application of algorithms or operators (Goel, 1995). In other words, essentially the design process is a problem-solving process. Moreover, design creativity has been investigated in relation to the design process (Nagai \& Taura, 2006) and the design solution (Dorst \& Cross, 2001).

According to Lockwood (2010, p. 5), design thinking is "a human-centered innovation process that emphasizes observation, collaboration, fast learning, visualization of ideas, rapid concept prototyping, and concurrent business analysis." This definition focuses on the application of professional designers' espoused work process. According to a literature review work by Micheli et al.(2019), design thinking has been widely considered a problem-solving means. Therefore, it could be inferred that, if design thinking is regarded as a planning process for solving problems, the ability to design creatively may be viewed as a key element influencing the process or outcome of design thinking.

\subsection{Personality Traits}

Personality psychologists generally agree that personality is linked to actual behavior through cognitive processes that determine one's motivation to engage in a particular act (Devaraj et al., 2008). And, personality type is a stable individual difference that is related to many human behaviors (Cabrera et al., 2006; Wang \& Yang, 2007; Matzler et al., 2011; Von Hippel, 2016).

In a study on the relationship between personality traits and successful free innovation in the household sector, personality traits were found that were significantly associated with free innovation (Von Hippel, 2016). In the study, a series of innovation processes were divided into three stages. Personality traits such as openness to experience, introversion and conscientiousness were examined in relation to the innovation process. The results suggested that personality traits differed significantly from stage to stage (Von Hippel, 2016).

In addition, Several studies have focused on the relationship between an individual's personality and his or her intention to share knowledge (Cabrera et al., 2006; Wang \& Yang, 2007; Matzler et al., 2011). For instance, Cabrera et al. (2006) found a significant positive association of three dimensions, FFMagreeableness, openness to experience and conscientiousness, with the intention to share knowledge. Similarly, the study by Matzler et al. (2011) reported same result as Cabrera et al. (2006) found with the exception of the influence of openness to experience (Wang \& Yang, 200).

Moreover, personality has been investigated in relation to design creativity (Hanna \& Barber, 2001; Toh \& Miller, 2016). It has been found that creative artists tend to have a preference for complexity, asymmetry and incompleteness (Hanna \& Barber, 2001). Personality traits have also been examined which have an influence on creative concept selection in design process (Toh \& Miller, 2016). For instance, an empirical study revealed that design teams which have higher levels of conscientiousness, agreeableness, and tolerance for ambiguity are more prone to select novel concepts (Toh \& Miller, 2016).

However, a question that has yet to be addressed is whether personality has an influence on the utilization of design thinking. More empirical research is needed to gain insight into individual differences in design problem solving.

\section{Theoretical model and hypotheses}

\subsection{Five-Stage Model of Design Thinking}

In this research, we focus on the five-stage design thinking model proposed by d.school, which is comprised of Empathize, Define (the problem), Ideate, Prototype, and Test. Furthermore, we use the FFM to examine the relationship between the capacity to utilize design thinking and individual personality traits. 
The first stage of the design-thinking process, which is Empathize, is a step for gaining an empathic understanding of the problem that is to be solved. Then, during the Define stage, we put together the information we have created and gathered during the Empathize stage. This is where we analyze our observations and synthesize them in order to define the core problems that we and our team have identified up to this point. Next, during the third stage of Ideate, it is important to get as many ideas or problem solutions as possible at the beginning of the Ideation phase. The fourth stage of Prototype is an experimental phase where the aim is to identify the best possible solution for each of the problems identified during the first three stages. Lastly, Test is the final stage of the 5 stage-model, but this is an iterative process.

\subsection{Five-Factor Model of Personality traits}

There are many dimensions in personality. The FFM (also known as Big Five model) is currently one of the most widely used approaches for describing personality, and the five variables have been proved to be quite stable (Wang \& Yang, 2007; Von Hippel, 2016). It is composed of openness to experience, extraversion, conscientiousness, agreeableness, and neuroticism.

Openness to experience is related to imagination, curiosity, artistic sensitivity, and originality (Cabrera et al., 2006). Extraversion is a measure of the extent to which people are assertive, dominant, energetic, active, talkative, and enthusiastic (Zhao \& Seibert, 2006; LePine \& Van Dyne, 2001; Lucas et al., 2000). Conscientiousness is linked to people's degree of efficiency, persistence, hard work, and motivation in the pursuit of goal accomplishment (Zhao \& Seibert, 2006). Agreeableness describes people's interpersonal orientation (Von Hippel, 2016). Neuroticism is a measure of affect and emotional control. High levels of neuroticism increase the likelihood of experiencing negative emotions whereas low levels indicate emotional stability (LePine \& Van Dyne, 2001).

Accordingly, based on the definition of personality traits and features of the five-stage model of design thinking, we propose the following hypothesis:

- Hypothesis A: Openness to experience is positively associated with the Ideate stage.

- Hypothesis B: Extraversion is positively associated with the Empathize stage.

- Hypothesis C: Conscientiousness is positively associated with the Define stage.

- Hypothesis D: Agreeableness is positively associated with the Empathize stage.

- Hypothesis E: Neuroticism is not significantly associated with every stage of design thinking.

\section{Method}

\subsection{Participants}

Recruited with the assistance of a dean at a large comprehensive university in Taiwan, the People's Republic of China, 28 (7 male and 21 female) students took part in the study. These students had participated in workshops on design thinking or taken design thinking class. These students ranged in age from twenties to forties. Furthermore, most of the students were studying in academic fields related to industrial design $(75 \%)$.

\subsection{Measures}

All participants responded to two self-report inventories in Chinese. The first part was a self-evaluation of their own design-thinking capability. Based on design-thinking principles drawn from prior literature, we constructed an instrument to assess individuals' design-thinking capability, which was comprised of 15 items. Two of these items assessed the implementation of Empathize, two items measured the stage of Define, five items assessed Ideate, two items measured Prototype, and the remaining four items measured the stage of Test (e.g. "During the interview, I successfully managed to read between the lines by paying attention non-verbal expressions such as facial expressions, gestures, and voice tone, and tried to figure out what the speaker truly wanted to say."). Participants rated themselves on a sevenpoint Likert scale.

The second inventory was the TIPI-C ( $\mathrm{Li}, 2013)$. In this study, we measured survey respondents' traits of FFM constructs with the Chinese version of Ten-Item Personality Inventory (TIPI-C) verified by Li 
(2013), which was based on the TIPI items (Gosling et al., 2003) and comprised 10 statements. It is a well validated measure of the FFM that has been extensively used in psychology research (Gosling et al., 2003; Oshio et al., 2012; Li, 2013). The participants rated themselves on a seven-point Likert scale.

\section{Results}

Table 1 presents the results of an analysis of the correlation between FFM and the five-stage designthinking model. Results of the Pearson correlation indicated that there was a significant positive correlation between extraversion and the Ideate stage, $(\mathrm{r}(28)=.482, \mathrm{p}=.008)$, as well as conscientiousness and the Define stage, $(\mathrm{r}(28)=.443, \mathrm{p}=.044)$.

Additionally, relationships between FFM and combinations of every stage of design thinking were examined. These results are given in Table 2 and indicate that extraversion is also positively correlated with the combined design processes of 'EDI' (Empathy +Define +Ideate) $[\mathrm{r}(28)=.445, \mathrm{p}=.007]$ and combination of 'DI' (Define +Ideate) $[\mathrm{r}(28)=.48, \mathrm{p}=.013]$. In addition, there was a significant positive correlation between conscientiousness and 'DI' (Define +Ideate) $[\mathrm{r}(28)=.394, \mathrm{p}=.035]$ and 'DIP' (Define +Ideate +Prototype) $[\mathrm{r}(28)=.393, \mathrm{p}=.031]$

According to Table 1, Hypothesis A, Hypothesis B, and Hypothesis D were rejected. In contrast, Hypothesis C and Hypothesis E were supported.

Table 1. Correlation coefficients: five-stage model of design thinking with personality traits

\begin{tabular}{|c|c|c|c|c|c|c|c|c|c|c|}
\hline & 1 & 2 & 3 & 4 & 5 & 6 & 7 & $\mathbf{8}$ & 9 & 10 \\
\hline 1 Empathize & 1 & & & & & & & & & \\
\hline 2 Define & 0.345 & 1 & & & & & & & & \\
\hline 3 Ideate & $.456^{*}$ & $.552^{* *}$ & 1 & & & & & & & \\
\hline 4 Prototype & $.413^{*}$ & $.451^{*}$ & $.380^{*}$ & 1 & & & & & & \\
\hline 5 Test & 0.217 & 0.142 & 0.327 & $.706^{* *}$ & 1 & & & & & \\
\hline 6 Extraversion & 0.211 & 0.371 & $.482^{* *}$ & -0.013 & -0.030 & 1 & & & & \\
\hline 7 Agreeableness & -0.228 & -0.213 & -0.213 & 0.224 & 0.108 & -0.279 & 1 & & & \\
\hline 8 Conscientiousness & 0.039 & $.443^{*}$ & 0.240 & 0.254 & 0.053 & 0.003 & 0.127 & 1 & & \\
\hline 9 Neuroticism & -0.318 & -0.161 & -0.068 & -0.094 & 0.122 & 0.033 & 0.355 & 0.221 & 1 & \\
\hline 10 Openness to experience & -0.212 & 0.132 & 0.076 & 0.057 & 0.120 & -0.041 & -0.017 & 0.333 & $.460^{\circ}$ & 1 \\
\hline
\end{tabular}

Table 2. Correlation coefficients: combined stages of design thinking with personality traits

\begin{tabular}{|c|c|c|c|c|c|c|c|c|c|}
\hline & ED & EDI & EDIP & DI & DIP & DIPT & IP & IPT & PT \\
\hline Extraversion & 0.359 & $.445^{*}$ & 0.337 & $.48^{*}$ & 0.337 & 0.256 & 0.26 & 0.164 & -0.023 \\
\hline Agreeableness & -0.269 & -0.274 & -0.132 & -0.242 & -0.074 & -0.022 & 0.025 & 0.063 & 0.181 \\
\hline Conscientiousness & 0.304 & 0.31 & 0.328 & $.394 *$ & $.393 *$ & 0.328 & 0.298 & 0.224 & 0.168 \\
\hline Neuroticism & -0.288 & -0.23 & -0.21 & -0.133 & -0.136 & -0.067 & -0.098 & -0.015 & 0.013 \\
\hline Openness to experience & -0.04 & 0.002 & 0.022 & 0.12 & 0.111 & 0.128 & 0.079 & 0.104 & 0.095 \\
\hline
\end{tabular}

\section{Conclusion and discussion}

The principal goal of this study was to explore relationships between personality traits and capacity for utilizing design thinking. The study results were partially, although not completely, supportive of the predictions.

First, even though it was predicted that the extraversion dimension was not significantly related to the Empathize stage, it can be noted that extraversion had a significant positive correlation with the Ideate stage. Extraversion is a trait that describes a person's assertiveness, emotional expression, and comfort levels in social situations. People with high extraversion tend to be adventurous, assertive, frank, sociable and talkative, whereas individuals who have low extraversion may be described as quiet, reserved, or independent (McCrae \& Costa, 1987; Zhao \& Seibert, 2006). People who identify as 
extroverts tend to search for novel experiences and social connections that allow them to interact with other individuals as much as possible. They also tend to feel comfortable in appropriately expressing emotions and making their opinion heard. Therefore, in teamwork, the more extroverts, who tend to be energetic and talkative, on a team, the higher the possibility they can stimulate idea creation in other members, enabling the generation of a variety of useful ideas. Moreover, according to the analysis results in Table 2, it may be inferred that extraversion is not only closely related to the Ideate stage, but also closely related to the "definition + creative" process. This indicates that someone who is highly extroverted can define a problem more accurately and show greater vitality during the Ideate stage.

Second, the results show a strong and significant positive correlation between conscientiousness and Define stage, which indicates that someone who scores high on this trait is able to analyze collected information about users more accurately during the Define stage and formulate a precise definition of the requirements and users' questions. Conscientiousness is a trait that describes a person's ability to engage in goal-oriented behavior, exert control over his impulses, and is thoughtful overall. Individuals with high conscientiousness like planned rather than spontaneous behavior, whereas those having a low level tend to find it hard to make systematic progress (Barrick et al., 2001). They are thoughtful, goaloriented, detail-oriented, and have good impulse control in the eyes of others. These people also practice mindfulness. They live in the moment and understand that their behavior and choices can affect others. Accordingly, it can be imagined that, when defining a problem, the implementer needs to possess good organizational and logic skills as well as be meticulous in order to find the crux easier and more accurately. Furthermore, according to the analysis results in Table 2, it is significant to note that, conscientiousness is positively related to the process of "definition + creativity." The relationship suggested that people who score high on conscientiousness and are characterized as "efficient, meticulous, confident, and intelligent" can more accurately define where the user's pain points are at this stage. They can also brainstorm more efficiently during the Ideate stage, and finally propose solutions.

In contrast to these significant results, no significant correlation was found between openness to experience and the Ideate stage, or agreeableness and the Empathize stage. These were the most unexpected results of this study. Openness to experience is characterized by traits such as being openminded, curious, analytical, and theoretically-oriented. People with high openness to experience like novelty, and are creative, innovative, imaginative, reflective, and untraditional (McCrae \& Costa, 1987). In contrast, people with low openness are conventional, conservative and prefer familiarity (Heinström, 2003). Therefore, this was assumed to be most closely correlated to success or failure at the Ideate stage. However, the results showed no correlation between the two dimensions, which indicated that not everyone who scores high on openness to experience can always facilitate idea creation and come up with the best solution during the Ideate stage. In addition, individuals with high agreeableness are modest, trusting, forgiving, altruistic, and caring (Zhao \& Seibert, 2006; Barrick et al., 2001). These people usually feel empathy and concern for other people. Therefore, it can be assumed that an agreeable individual is more likely to resonate with the user, and be better able to perceive what difficulties the user has from the standpoint of the user. However, contrary to our prediction, a negative correlation was found with Empathize. This suggests that people who score higher on agreeableness are not likely to resonate with users. Although the experimental results were not significant, they still have some reference value.

Finally, the absence of a significant correlation between neuroticism and design thinking suggested that no matter whether a person has high neuroticism or not, this trait will not impact the final result when design-thinking activity is carried out. Neuroticism is typically defined as a tendency toward anxiety, depression, self-doubt, and other negative feelings. People with high neuroticism are reactive and more easily bothered by stimuli in their environment. In contrast, people with low neuroticism have emotional stability, but they also tend to be insensitive and are likely to underestimate risk and engage in risky behavior (Zhao \& Seibert, 2006). According to the results, none of these characteristics affects the practice of design thinking activities. 


\section{Contributions and limitation}

This study has made two contributions. First, from a theoretical perspective, this study provides some new insights for related research on design thinking. Most of the research on design thinking so far has focused on the macro-level of enterprises or organizations, while this study focuses on the personality traits of participants in design thinking activities from a micro-perspective. In addition to individuals' creativity, personality can be regarded as an important element in design-thinking work. From this perspective, it presents the possibility of connecting design thinking with individual personality and design creativity. For example, exploring mediation or moderation effects among these three elements. In addition, the correlation between personality and combined stages of design thinking provides us with a new angle for understanding the design-thinking process from a holistic viewpoint. Second, from an empirical perspective, this study reveals the possibility of implementing "personality" as a reference element when companies conduct design-thinking training activities. For example, before a design-thinking workshop, participants can be tested using a personality inventory. Based on the test results, participants who score high on extraversion and conscientiousness can be equally assigned to each group to facilitate progress in the design-thinking activity.

Similarly, the present study has its limitations. First, because the sample size is insufficient, we failed to detect any significance for most of our hypotheses, and the experimental results lack persuasiveness. In addition, as our model was pioneered in this study, further testing is necessary to verify the validity of this instrument. Moreover, our evaluation of individuals' capacity for utilizing design thinking is confined to participants' self-evaluations, which lack objectivity. According to this, further empirical study is essential to explore this issue.

\section{References}

Barrick, M. R., Mount, M. K., \& Judge, T. A. (2001). Personality and performance at the beginning of the new millennium: What do we know and where do we go next?. International Journal of Selection and Assessment, 9(1-2), 9-30.

Boland, R. (2004). Managing as designing (pp. 164-168). F. Collopy (Ed.). Redwood City, CA: Stanford University Press.

Brooks Jr, F. P. (2010). The design of design: Essays from a computer scientist. Pearson Education.

Brown, T. (2009). Change by design: How design thinking transforms organizations and inspires organization. NY.

Cabrera, A., Collins, W. C., \& Salgado, J. F. (2006). Determinants of individual engagement in knowledge sharing. The International Journal of Human Resource Management, 17(2), 245-264.

Coyne, R. (1995). Designing information technology in the postmodern age: From method to metaphor. Mit Press. Cross, N., Dorst, K., \& Christiaans, H. (Eds.). (1996). Analysing design activity. Wiley.

Cross, N., Dorst, K., \& Roozenburg, N. (1992). Research in design thinking. Delft University Press.

Csikszentmihalyi, M. (1997). Flow and the psychology of discovery and invention. HarperPerennial, New York, 39.

Devaraj, S., Easley, R. F., \& Crant, J. M. (2008). Research note-how does personality matter? Relating the fivefactor model to technology acceptance and use. Information Systems Research, 19(1), 93-105.

Dorst, K., \& Cross, N. (2001). Creativity in the design process: co-evolution of problem-solution. Design studies, 22(5), 425-437.

Goel, V. (1995). Sketches of thought. MIt Press.

Gosling, S. D., Rentfrow, P. J., \& Swann Jr, W. B. (2003). A very brief measure of the Big-Five personality domains. Journal of Research in personality, 37(6), 504-528.

Hanna, R., \& Barber, T. (2001). An inquiry into computers in design: attitudes before-attitudes after. Design studies, 22(3), 255-281.

Hawthorne, G., Quintin, E. M., Saggar, M., Bott, N., Keinitz, E., Liu, N., .. \& Reiss, A. L. (2014). Impact and sustainability of creative capacity building: the cognitive, behavioral, and neural correlates of increasing creative capacity. In Design thinking research (pp. 65-77). Springer, Cham.

Heap, J. (1989). The management of innovation and design. London: Cassell

Heinström, J. (2003). Five personality dimensions and their influence on information behaviour. Information research, 9(1), 9-1. 
Johansson, U. (2010). How to avoid throwing the baby out with the bath water: An ironic perspective on design thinking. EGOS Colloquim 2010, 30 June 30-3 July, Lisbon, Portugal.

Johansson-Sköldberg, U., Woodilla, J., \& Çetinkaya, M. (2013). Design thinking: past, present and possible futures. Creativity and innovation management, 22(2), 121-146.

Junginger, S. (2007). Learning to design: giving purpose to heart, hand and mind. Journal of Business Strategy, 28(4), 59-65.

LePine, J. A., \& Van Dyne, L. (2001). Voice and cooperative behavior as contrasting forms of contextual performance: evidence of differential relationships with big five personality characteristics and cognitive ability. Journal of applied psychology, 86(2), 326.

Li, J. D. (2013). Psychometric properties of ten-item personality inventory in China. China Journal of Health Psychology, 21(11), 1688-1692.

Liedtka, J. (2000). In defense of strategy as design. California Management Review, 42(3), 8-30.

Liedtka, J. (2010). Business strategy and design: can this marriage be saved? Design Management Review, 21(2), 6-11.

Liedtka, J. T. (2000). In Defence of Strategy as Design. California Management Review.

Lockwood, T. (2010). The bridge between design and business. Design Management Review, 21(3), 5-5.

Lucas, R. E., Diener, E., Grob, A., Suh, E. M., \& Shao, L. (2000). Cross-cultural evidence for the fundamental features of extraversion. Journal of personality and social psychology, 79(3), 452.

Luchs, M. G., Swan, K. S., \& Creusen, M. E. (2016). Perspective: A review of marketing research on product design with directions for future research. Journal of Product Innovation Management, 33(3), 320-341.

March, J. G. (1991). Exploration and exploitation in organizational learning. Organization science, 2(1), 71-87.

Martin, R. (2007). Design and business: why can't we be friends? Journal of Business Strategy, 28(4), 6-12.

Martin, R., \& Martin, R. L. (2009). The design of business: Why design thinking is the next competitive advantage. Harvard Business Press.

Matzler, K., Renzl, B., Mooradian, T., von Krogh, G., \& Mueller, J. (2011). Personality traits, affective commitment, documentation of knowledge, and knowledge sharing. The International Journal of Human Resource Management, 22(02), 296-310.

McCrae, R. R., \& Costa, P. T. (1987). Validation of the five-factor model of personality across instruments and observers. Journal of personality and social psychology, 52(1), 81.

Micheli, P., Wilner, S. J., Bhatti, S. H., Mura, M., \& Beverland, M. B. (2019). Doing design thinking: Conceptual review, synthesis, and research agenda. Journal of Product Innovation Management, 36(2), 124-148.

Nagai, Y., \& Taura, T. (2006). FORMALDESCRIPTION OF CONCEPT-SYNTHESIZING PROCESS FOR CREATIVE DESIGN. In Design computing and cognition'06 (pp. 443-460). Springer, Dordrecht.

Oshio, A., Shingo, A. B. E., \& Cutrone, P. (2012). Development, Reliability, and Validity of the Japanese Version of Ten Item Personality Inventory (TIPI-J). Japanese Journal of Personality, 21(1).

Rowe, P. G. (1987). Design thinking. MIT press.

Toh, C. A., \& Miller, S. R. (2016). Creativity in design teams: the influence of personality traits and risk attitudes on creative concept selection. Research in Engineering Design, 27(1), 73-89.

Von Hippel, E. (2016). Free innovation. MIT press.

Wang, C. C., \& Yang, Y. J. (2007). Personality and intention to share knowledge: An empirical study of scientists in an R\&D laboratory. Social Behavior and Personality: an international journal, 35(10), 1427-1436.

Zhao, H., \& Seibert, S. E. (2006). The Big Five personality dimensions and entrepreneurial status: A metaanalytical review. Journal of applied psychology, 91(2), 259. 